\title{
Correlation of Age and Bone Marrow Derived CD 34+ Cells and Leucocytes in 873 Patients.
}

\section{Christof Pabinger ( $\square$ pabinger@opz.at )}

Medical University of Innsbruck https://orcid.org/0000-0003-4622-9399

\section{Dietmar Dammerer}

Medical University of Innsbruck: Medizinische Universitat Innsbruck

\section{Harald Lothaller}

University of Music and Performing Arts Graz Library: Universitat fur Musik und darstellende Kunst Graz Bibliothek

\section{Sandra Gieringer}

Institute for Regenerative Medicine Graz

Marcel Krall

Institute for Regenerative Medicine Graz

\section{Georg Stefan Kobinia}

Institute for Regenerative Medicine Graz

\section{Research}

Keywords: Stem cells, Leucocytes, Arthritis, Regenerative Medicine, Bone marrow derived stem cell therapy

Posted Date: September 8th, 2020

DOI: https://doi.org/10.21203/rs.3.rs-70184/v1

License: (c) (i) This work is licensed under a Creative Commons Attribution 4.0 International License.

Read Full License 


\section{Abstract}

\section{Background:}

The use of regenerative medicine, such as autologous chondrocyte implantation (ACl), matrix associated stem cell therapy (MAST) and bone marrow derived stem cell therapy against arthritis is the gold standard for certain indications. However, the clinical improvement of patients using these novel therapies remains heterogeneous and the reasons for this are not fully understood.

The impact of age is always a concern for patients and doctors and elderly patients can only be mobilized with lower total collected CD34+ cells, older age correlates with inferior results, fatty degeneration of the bone marrow, delayed fracture-healing and osteoporosis, but solid data are missing.

\section{Purpose:}

This is the first study to determine the average quantity of leukocytes and CD 34+ cells and their relationship in human bone marrow.

Study design: Descriptive Laboratory Study

Methods:

We evaluated the laboratory results of 873 patients (aged 1-90 years), who underwent stem cell transplantation for non malignant diseases.

$\underline{\text { Results: }}$

We found no age-related decrease regarding the number and the vitality of leukocytes and CD 34+ stem cells. The number of bone marrow derived leucocytes and CD 34+ cells showed a strong and significant correlation.

Conclusion:

The amount of bone marrow derived stem cells can be predicted by leukocytes. This study makes further research possible in order to link clinical outcome to the absolute number of stem cells and leukocytes.

An upper age-limit for stem cell therapy can therefore not be defined from the donor-site perspective.

\section{Clinical Relevance:}

The number of leucocytes might be used to predict the amount of stem cells in order to select the ideal patient.

\section{What Is Known About The Subject}


Cartilage undergoes remarkable alterations in composition, organization, and mechanical properties with aging. Therefore several cartilage restoring methods have been established in the past (ACl, MAST, etc.). Regardless of the purpose of a cell therapy, successful cell transplantations require the use of a sufficient number of specific cells and their engraftment. Specific qualitative age-dependent findings were published up to now, but it the quantity of stem cells according to age has not yet been studied sufficiently. To our knowledge this is the first study, assessing viability and quantitative number of stem cells over age in approximately 1000 patients.

\section{What this study adds to existing knowledge:}

Based on our findings, no upper age limit can be derived from a quantitative point of view. Furthermore we found a strong correlation between leukocytes and bone marrow derived CD+ stem cells. This is the first study to determine the average quantity of leukocytes and CD 34+ cells and their relationship in human bone marrow. We also found an inter-individual variation of cell number. This study makes further research possible in order to link clinical outcome to the absolute number of stem cells and leukocytes.

\section{Introduction}

The use of cell therapy, such as autologous chondrocyte implantation (ACl) and matrix associated stem cell therapy (MAST) for the repair of damaged cartilage is well established, demonstrating good short to medium term outcomes. ${ }^{9,} 24$ However, the clinical improvement of patients using these novel therapies remains heterogenous and the effects are not fully understood. Recently bone marrow derived stem cells gained further attraction in orthopedic diagnoses, where they are also used as bone marrow aspirate (BMA) or bone marrow aspirate concentration (BMAC) for stem cell therapy.

(1) Arthritis is treated in this way, aiming to generate additional cartilage, and stop the inflammatory process. $8,11,12,18,27,31,33,35$

(2) In patients with spinal cord injuries, bone marrow derived stem cells can improve some neural function. $6,7,13,15,17,23$

Regardless of the purpose of a cell therapy, successful cell transplantations requires the use of a sufficient number of specific cells and their engraftment. ${ }^{20}$ Better clinical results can be achieved with a higher donor-site stem cell count ${ }^{19,30}$ and a lower age. ${ }^{14}$ The impact of age is not fully understood for stem cell procedures and controversial:

Specific qualitative age-dependent findings were published up to now (lower proliferation and extra cellular matrix forming potential ${ }^{16}$, decreasing growth rate and telomere length, ${ }^{4}$ lower mobilization rate, ${ }^{1,}$ 28 fatty degeneration of the bone marrow, delayed fracture-healing and osteoporosis, ${ }^{21}$ acquired mitochondrial DNA mutations ${ }^{34}$ ) but the quantity of stem cells according to age has not yet been studied sufficiently. In hemato-oncology is is known, that grafts from older donors do not adversely affect 
outcomes of allogeneic hematopoietic cell transplantation as compared to grafts from younger donors in. ${ }^{10,28}$

Since an age-dependent range of the physiological leukocyte- and stem-cell-numbers and their vitality in the human bone marrow has not yet been reported and most clinical studies about CD 34+ stem cells refer to patients with malignant diseases, we wanted to establish a normal range of bone marrow derived leukocytes and stem cells of patients without malignancies according to age, harvested by bone amrrow aspiration (BMA).

Therefore the aim of this study is, to

- evaluate the number and the vitality of bone marrow derived leukocytes and CD 34+ cells in a large number of patients undergoing autologous stem cell transplantation for nonmalignant diseases

- study the connection to age in order to find out, if a possible

- age limit is present, after which cell number and vitality decreases.

- predictor exists for the amount of CD $34+$ cells in the bone marrrow.

\section{Material And Methods}

\section{Level Ilb: Retrospective cohort study}

In a retrospective study the laboratory results all patients, who underwent stem stell transplantation for non malignant diseases were evaluated. All bone marrow punctures were done by the same surgeon (K.G.). The stem cells were harvested with a Yamshidi Needle (15 ga x 2.688in MAX Bone Marrow Aspiration Needle, ARGON Medical devices, Athens, USA, www.argonmedical.com) under sedoanalgesia and in compliance with all applicable laws and regulations. $90 \mathrm{ml}$ of bone marrow aspirate was retrieved using the Technique of Kristin Oliver $^{26}$ (using $10 \mathrm{ml}$ syringes and changing direction repeatedly). One milliliter of this sample was immediately transferred to a laboratory and analyzed with FACS (Fluorescence Activated Cell sorter) using a stem Cell Kit from Beckman Coulter and the ISHAGE protocol (https://www.bc-cytometry.com/PDF/DataSheet/IM3630.pdf).

\section{Inclusion criteria were:}

- Age between 1 and 90 years

- Bone marrow puncture

\section{Exclusion criteria were:}

- Malignant disease 
- Known autoimmune disease

- Inflammatory disease

- Prior bone marrow stimulation or treatment with GCSF (granulocyte colony stimulating factor)

- Prior treatment with hormons or corticoids in the last 6 months

\section{Statistical Analysis was done using:}

- Pearson's chi-squared tests

- One-way analyses of variance (with post-hoc Bonferroni-adjusted pairwise comparisons of estimated marginal means)

- Pearson`s Correlation

\section{Results}

873 datasets were found in the laboratory patient database. Age ranged from 1-90 years (mean 28, median 25) and patients were clustered into age groups of 10 years. Gender distribution was $29 \%$ female and $71 \%$ male. There was no gender-difference. The anonymous laboratory data was statistically evaluated by a blinded observer. (Table 1 )

Table 1

Age distribution of bone marrow derived cells

\begin{tabular}{|c|c|c|c|c|c|}
\hline & \multirow[b]{2}{*}{$\mathbf{n}$} & \multirow[b]{2}{*}{ gender } & \multicolumn{3}{|c|}{ bone marrow derived cell analysis } \\
\hline & & & $\begin{array}{l}\text { Leukocyte } \\
\text { cell count }\end{array}$ & $\begin{array}{l}\text { Leukocyte } \\
\text { vitality }\end{array}$ & $\begin{array}{l}\mathrm{CD} 34+\text { cell } \\
\text { count }\end{array}$ \\
\hline Age & 873 & male & count $/ \mathrm{nl}$ & $\%$ & count $/ \mu$ \\
\hline$<10$ & 296 & $71 \%$ & $19( \pm 16)$ & $87( \pm 9)$ & $298( \pm 299)$ \\
\hline $11-20$ & 102 & $74 \%$ & $14( \pm 8)$ & $86( \pm 8)$ & $147( \pm 134)$ \\
\hline $21-30$ & 89 & $72 \%$ & $14( \pm 7)$ & $84( \pm 16)$ & $125( \pm 106)$ \\
\hline $31-40$ & 92 & $80 \%$ & $11( \pm 6)$ & $86( \pm 9)$ & $97( \pm 69)$ \\
\hline $41-50$ & 109 & $75 \%$ & $14( \pm 8)$ & $91( \pm 3)$ & $90( \pm 73)$ \\
\hline $51-60$ & 98 & $72 \%$ & $8( \pm 4)$ & $85( \pm 13)$ & $94( \pm 149)$ \\
\hline $61-90$ & 86 & $51 \%$ & $7( \pm 2)$ & $86( \pm 7)$ & $79( \pm 89)$ \\
\hline mean & 28 & $71 \%$ & $16( \pm 13)$ & $87( \pm 9)$ & $183( \pm 226)$ \\
\hline
\end{tabular}

\section{Bone marrow derived leucocyte cell count}

No significant differences between age and gender and no interaction. Even in a pairwise comparison of patients below the age of 20 versus patients at the age of 20 years and over, no significant differences 
were found $(p=.9)$. The correlation between age and bone marrow derived leucocyte cell count is negligible $(r=-.255, p<.001$, Figure 1$)$.

\section{Bone marrow derived leucocyte vitality.}

No significant differences between age and gender and no interaction in all age groups, no significant correlation. (Table 1)

\section{Bone marrow derived CD34+ cell count}

No significant differences between age and gender and no interaction. Even in a pairwise comparison of patients below the age of 20 versus patients at the age of 20 years and over, no significant differences were found $(p=.8)$. The correlation between age and bone marrow derived CD $34+$ cell count is negligible and comes from patients below the age of 10 years $(r=-.361, p<.001$, Figure 2$)$.

\section{Correlation / Predictor}

The number of bone marrow derived leucocytes and CD 34+ cells (as a subset of leucocytes, respectively) had a great variation between individual patients, but both cell types correlated strong and significant $\left(p<.001, r^{2}=822\right.$, Figure 3$)$ within the respective patients. Bone marrow derived leukocytes are therefore a viable predictor for the amount of stem cells. The number of stem cells can be calculated as follows:

\section{Stem cells (CD 34+ cells / Microliter) = 13. 5 x Leukocytes (per Nanoliter bone marrow aspirate).}

Bone marrow derived leucocytes and and CD 34+ cells had a negligible tendency $(r=-.255, p<.001$ and $r=-.361, p<.001$ ) to decrease over life time. The weak correlation was only due to the group of children below the age of 10 years. Thereafter there was a variation between individual patients, but no decrease over time.

\section{Discussion}

Arthritis and musculoskeletal disorders constitute a major cause of disability and the burden of musculoskeletal diseases will increase with an increasing ageing population. ${ }^{22}$ Stem cells remain at the forefront of efforts in Regenerative Medicine, based on a conviction that this technology can provide an effective treatment paradigm for major diseases where there is still an unmet need. ${ }^{3}$

In 2017 the first prospective, single blind, placebo-controlled trial of bone marrow aspirate concentrate for knee osteoarthritis described a positive clinical outcome. ${ }^{31} \mathrm{~A}$ recent review of 1500 papers on stem cell therapy in orthopaedics revealed, that studies reported information on only $42 \%$ (range, $25 \%-60 \%$ ) of the variables included within established minimum reporting standards, leaving it unclear, which amount of 
stem cells was really harvested and injected. ${ }^{25,29} \mathrm{~A}$ higher donor-site cell count correlates with a better outcome. $8,14,18,19,27,35$ In hemato-oncology, where bone marrow transplantations are performed routinely since decades, elderly patients show inferior mobilization rates and inferior outcome in some studies. ${ }^{1,28,14}$ Likewise, in a mice model an age-related fatty degeneration of the bone marrow was described. ${ }^{21}$

The current study looked at the donor site of 873 healthy patients (without bone marrow diseases), applicable for orthopaedic interventions, to understand the vitality and the quality of the bone marrow derived (stem) cells.

\section{Age and cell counts}

Due to its large sample size this study is the first to establish a normal range of leukocytes and CD34+ stem cells in bone marrow aspirate (BMA) in the average population. The amount and vitality of bone marrow derived leucocytes and the number of mononuclear cells (stem cells) do not deteriorate over age. The formerly described lower mobilization rate of bone marrow derived (stem) cells in the elderly in some studies ${ }^{1,28}$ conflicts with a recent study, where little of the parameter variability could be explained by age. ${ }^{5}$ Our finding, that the number of bone marrow derived leucocytes remains stable in adults was confirmed in a prior study with 24 goats, but we did not find further papers referring to humans. ${ }^{2}$

\section{Vitality.}

The vitality of bone marrow derived cells was always high (87-91\%) in all age groups using FACS (fluorescence-activated cell sorting) analysis. Regarding dental pulp stem, the proliferation rate decreases in elderly patients. ${ }^{36}$ We could not confirm this finding in bone marrow derived cells. It is well known, that jawbones have an different bone metabolism. ${ }^{32}$

\section{Correlation / Predictor}

Stem cells are mononuclear cells and therefore a $7.4 \%$ fraction $(1 / 13.5)$ of the bone marrow derived leucocytes, as we demonstrated.

To our knowledge no prior study described the positive and strong correlation $\left(p<.001, r^{2}=822\right)$ between both parameters. Since stem cells can only be identified using specific CD antigen sets (CD 34, CD 90, CD 45, CD 107,...), which is costly and laborious, this correlation can be utilized, to predict the amount of stem cells based on the number of bone marrow derived leucocytes alone, which is much easier. As a matter of fact, only a negligible share of publications reports the absolute number of stem cells used per patient. ${ }^{29}$ Using the new described correlation, a much cheaper possibility exists, to assess, if a specific 
patient has a high or low stem cell number, since counting leukocytes can be done in any operating room, but counting stem cells requires at least a FACS analysis.

\section{Limitations:}

Since this was a retrospective study, we were not able to assess any social data (body weight, sport habits, smoking status,...). We did not perform colonization and differentiation experiments, since the lack of a specific MSC marker and the low frequency of MSCs in bone marrow necessitate their isolation by in vitro expansion.

Further research is needed to link clinical outcome with the absolute number of bone marrow derived leukocytes and stem cells since it is not yet clear, if the heterogenous clinical results of individual patients are linked to the heterogenous bone marrow derived stem cell counts. It remains speculative if patients with higher cell counts will have better outcomes and might therefore be better suitable for stem cell operations.

\section{Conclusion}

We established a normal range of bone marrow derived leukocytes and stem cells in 873 patients. No age-related decrease regarding the number and the vitality of leukocytes and stem cells was found. Furthermore the number of bone marrow derived leucocytes might be used to predict the amount of stem cells (usually a $7.4 \%$ share) on an individual basis in order to focus on the "ideal" patients.

\section{Declarations}

\section{- Ethics approval and consent to participate}

Use of anonymous secondary data, no trace to individual patients is possible. According to the declaration of Helsinky and the Ethics Commission of our University no informed consent necessary.

\section{- Consent for publication}

Approved by all authors.

\section{- Availability of data and material}

Free use of our data upon request.

\section{- Competing interests}

Nothing to declare. 


\section{- Funding}

No funding received.

\section{- Authors' contributions}

GK and CP contributed to the drafting and CP to writing and each author contributed to substancial review of this paper. HL did the statistic analysis. CP, HL, GS, MK produced the figures and tables. All authors have read and approved the final submitted manuscript

\section{- Acknowledgements}

Nothing to declare.

\section{References}

1. Al-Ali HK, Bourgeois M, Krahl R, et al. The impact of the age of HLA-identical siblings on mobilization and collection of PBSCs for allogeneic hematopoietic cell transplantation. Bone Marrow Transplant. 2011;46(10):1296-1302.

2. Baliu-Pique $M$, Kurniawan $H$, Ravesloot $L$, et al. Age-related distribution and dynamics of T-cells in blood and lymphoid tissues of goats. Dev Comp Immunol. 2019;93:1-10.

3. Barry F MSC Therapy for Osteoarthritis: An Unfinished Story. J Orthop Res. 2019;37(6):1229-1235.

4. Baxter MA, Wynn RF, Jowitt SN, Wraith JE, Fairbairn LJ, Bellantuono I. Study of telomere length reveals rapid aging of human marrow stromal cells following in vitro expansion. Stem Cells. 2004;22(5):675-682.

5. Brekkan A, Lopez-Lazaro L, Yngman G, et al. A Population Pharmacokinetic-Pharmacodynamic Model of Pegfilgrastim. AAPS J. 2018;20(5):91.

6. Bryukhovetskiy AS, Bryukhovetskiy IS. Effectiveness of repeated transplantations of hematopoietic stem cells in spinal cord injury. World J Transplant. 2015;5(3):110-128.

7. Cheng I, Park DY, Mayle RE, et al. Does timing of transplantation of neural stem cells following spinal cord injury affect outcomes in an animal model? J Spine Surg. 2017;3(4):567-571.

8. Chiari C, Walzer S, Stelzeneder D, Schreiner M, Windhager R. [Therapeutic utilization of stem cells in orthopedics]. Orthopade. 2017;46(12):1077-1090.

9. Chong PP, Selvaratnam L, Abbas AA, Kamarul T. Human peripheral blood derived mesenchymal stem cells demonstrate similar characteristics and chondrogenic differentiation potential to bone marrow derived mesenchymal stem cells. J Orthop Res. 2012;30(4):634-642.

10. Civriz Bozdag S, Bay M, Ayyildiz E, Topcuoglu P, Ilhan O. Older age and capacity of colony forming unit in autologous peripheral derived hematopoietic cells. Transfus Apher Sci. 2012;47(1):113-116. 
11. Confalonieri D, Schwab A, Walles H, Ehlicke F. Advanced Therapy Medicinal Products: A Guide for Bone Marrow-derived MSC Application in Bone and Cartilage Tissue Engineering. Tissue Eng Part B Rev. 2018;24(2):155-169.

12. Cotter EJ, Wang KC, Yanke AB, Chubinskaya S. Bone Marrow Aspirate Concentrate for Cartilage Defects of the Knee: From Bench to Bedside Evidence. Cartilage. 2018;9(2):161-170.

13. Dalamagkas $K$, Tsintou M, Seifalian AM. Stem cells for spinal cord injuries bearing translational potential. Neural Regen Res. 2018;13(1):35-42.

14. de Windt TS, Bekkers JE, Creemers LB, Dhert WJ, Saris DB. Patient profiling in cartilage regeneration: prognostic factors determining success of treatment for cartilage defects. Am J Sports Med. 2009;37 Suppl 1:58S-62S.

15. Deng J, Zhang Y, Xie Y, Zhang L, Tang P. Cell Transplantation for Spinal Cord Injury: Tumorigenicity of Induced Pluripotent Stem Cell-Derived Neural Stem/Progenitor Cells. Stem Cells Int. 2018;2018:5653787.

16. Erickson IE, van Veen SC, Sengupta S, Kestle SR, Mauck RL. Cartilage matrix formation by bovine mesenchymal stem cells in three-dimensional culture is age-dependent. Clin Orthop Relat Res. 2011;469(10):2744-2753.

17. Fan X, Wang JZ, Lin XM, Zhang L. Stem cell transplantation for spinal cord injury: a meta-analysis of treatment effectiveness and safety. Neural Regen Res. 2017;12(5):815-825.

18. Gangji V, Hauzeur JP, Matos C, De Maertelaer V, Toungouz M, Lambermont M. Treatment of osteonecrosis of the femoral head with implantation of autologous bone-marrow cells. A pilot study. J Bone Joint Surg Am. 2004;86-A(6):1153-1160.

19. Koh YG, Jo SB, Kwon OR, et al. Mesenchymal stem cell injections improve symptoms of knee osteoarthritis. Arthroscopy. 2013;29(4):748-755.

20. Kresnik PK, Krasna M, Rozman P, Vrtovec B, Malicev E. Collection and immunoselection of CD34 + cells: the impact of age, sex, and diabetes in patients with chronic heart failure. Transfusion. 2016;56(7):1792-1800.

21. Leucht $P$, Jiang J, Cheng $D$, et al. Wnt3a reestablishes osteogenic capacity to bone grafts from aged animals. J Bone Joint Surg Am. 2013;95(14):1278-1288.

22. Lewis R, Gomez Alvarez CB, Rayman M, Lanham-New S, Woolf A, Mobasheri A. Strategies for optimising musculoskeletal health in the 21(st) century. BMC Musculoskelet Disord. 2019;20(1):164.

23. Li XC, Zhong CF, Deng GB, Liang RW, Huang CM. Efficacy and safety of bone marrow-derived cell transplantation for spinal cord injury: a systematic review and meta-analysis of clinical trials. Clin Transplant. 2015;29(9):786-795.

24. Murphy EP, Fenelon C, Egan C, Kearns SR. Matrix-associated stem cell transplantation is successful in treating talar osteochondral lesions. Knee Surg Sports Traumatol Arthrosc. 2019.

25. Murray IR, Robinson PG, West CC, et al. Reporting Standards in Clinical Studies Evaluating Bone Marrow Aspirate Concentrate: A Systematic Review. Arthroscopy. 2018;34(4):1366-1375. 
26. Oliver K, Awan T, Bayes M. Single- Versus Multiple-Site Harvesting Techniques for Bone Marrow Concentrate: Evaluation of Aspirate Quality and Pain. Orthop J Sports Med. 2017;5(8):2325967117724398.

27. Orozco L, Munar A, Soler R, et al. Treatment of knee osteoarthritis with autologous mesenchymal stem cells: a pilot study. Transplantation. 2013;95(12):1535-1541.

28. Rezvani AR, Storer BE, Guthrie KA, et al. Impact of donor age on outcome after allogeneic hematopoietic cell transplantation. Biol Blood Marrow Transplant. 2015;21(1):105-112.

29. Robinson PG, Murray IR, West CC, et al. Reporting of Mesenchymal Stem Cell Preparation Protocols and Composition: A Systematic Review of the Clinical Orthopaedic Literature. Am J Sports Med. 2019;47(4):991-1000.

30. Schundeln MM, Walde G, Basu O, Havers W, Kremens B. Quantification of nucleated cells, CD34positive cells and CFU-GM colonies in single bone marrow samples and bone marrow harvests derived from healthy children. Pediatr Hematol Oncol. 2014;31(4):340-348.

31. Shapiro SA, Kazmerchak SE, Heckman MG, Zubair AC, O'Connor MIA, Prospective, Single-Blind, Placebo-Controlled Trial of Bone Marrow Aspirate Concentrate for Knee Osteoarthritis. Am J Sports Med. 2017;45(1):82-90.

32. Shibahara T Antiresorptive Agent-Related Osteonecrosis of the Jaw (ARONJ): A Twist of Fate in the Bone. Tohoku J Exp Med. 2019;247(2):75-86.

33. Spasovski D, Spasovski V, Bascarevic Z, et al. Intra-articular injection of autologous adipose-derived mesenchymal stem cells in the treatment of knee osteoarthritis. J Gene Med. 2018;20(1).

34. Su T, Turnbull DM, Greaves LC. Roles of Mitochondrial DNA Mutations in Stem Cell Ageing. Genes (Basel). 2018;9(4).

35. Vega A, Martin-Ferrero MA, Del Canto F, et al. Treatment of Knee Osteoarthritis With Allogeneic Bone Marrow Mesenchymal Stem Cells: A Randomized Controlled Trial. Transplantation. 2015;99(8):1681-1690.

36. Wu W, Zhou J, Xu CT, Zhang J, Jin YJ, Sun GL. Derivation and growth characteristics of dental pulp stem cells from patients of different ages. Mol Med Rep. 2015;12(4):5127-5134.

\section{Figures}




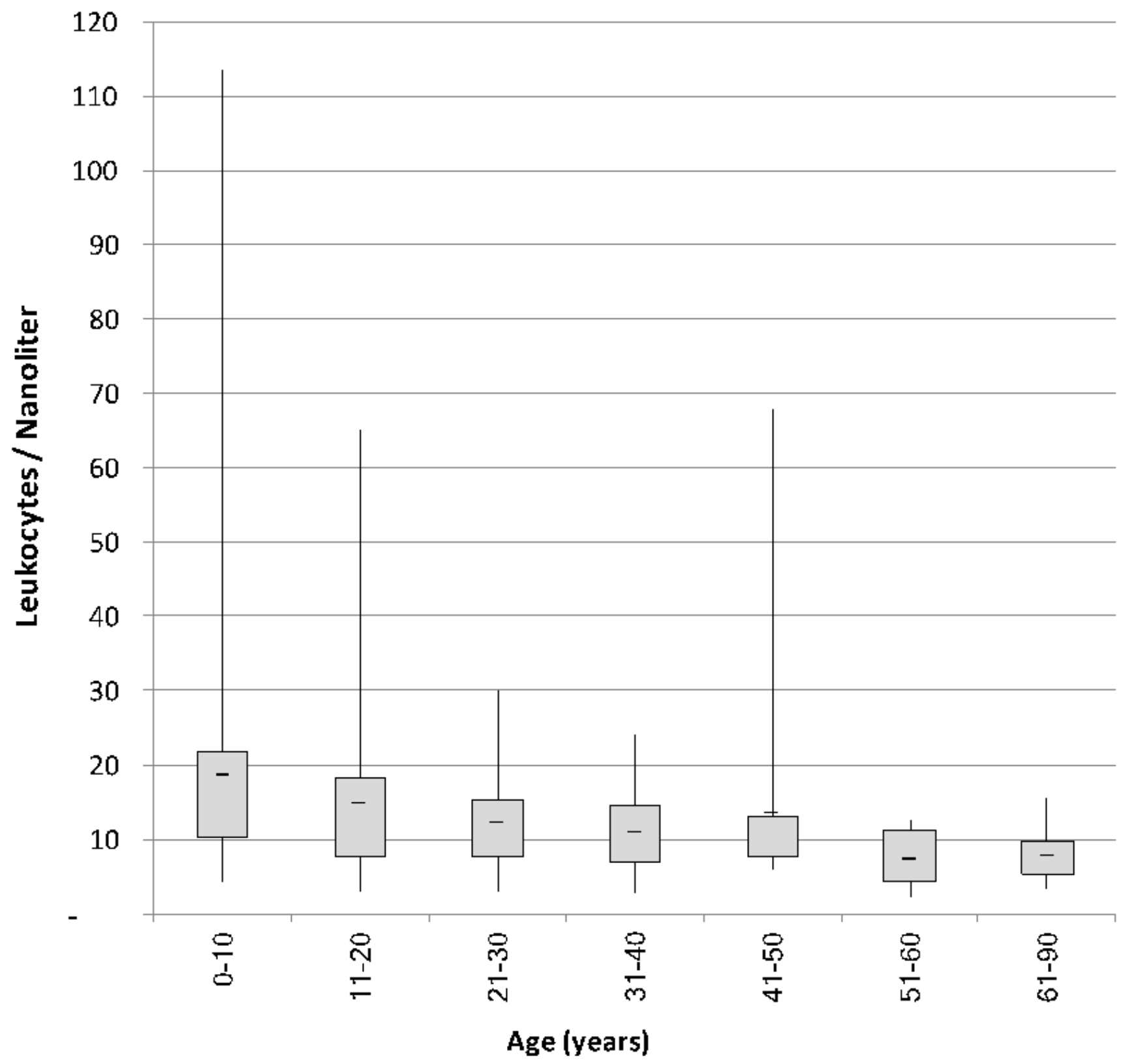

Figure 1

There is no relevant decrease of bone marrow derived leucocyte cell count with increasing age. 


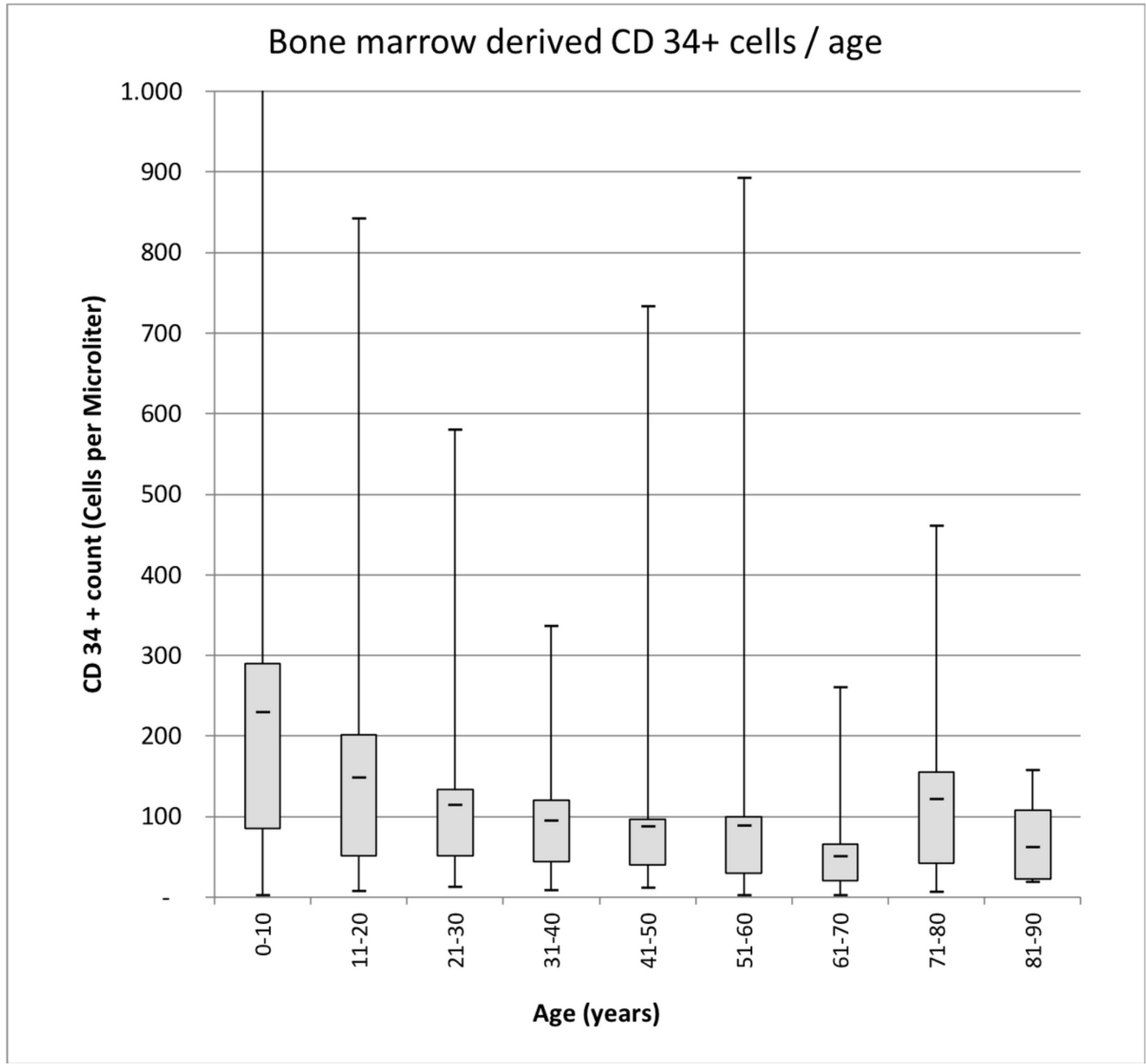

Figure 2

Even in elderly patients (up to 90 years) there is no relevant decrease of stem cells. 


\section{Bone marrow derived Leukocytes and CD34+ cells}

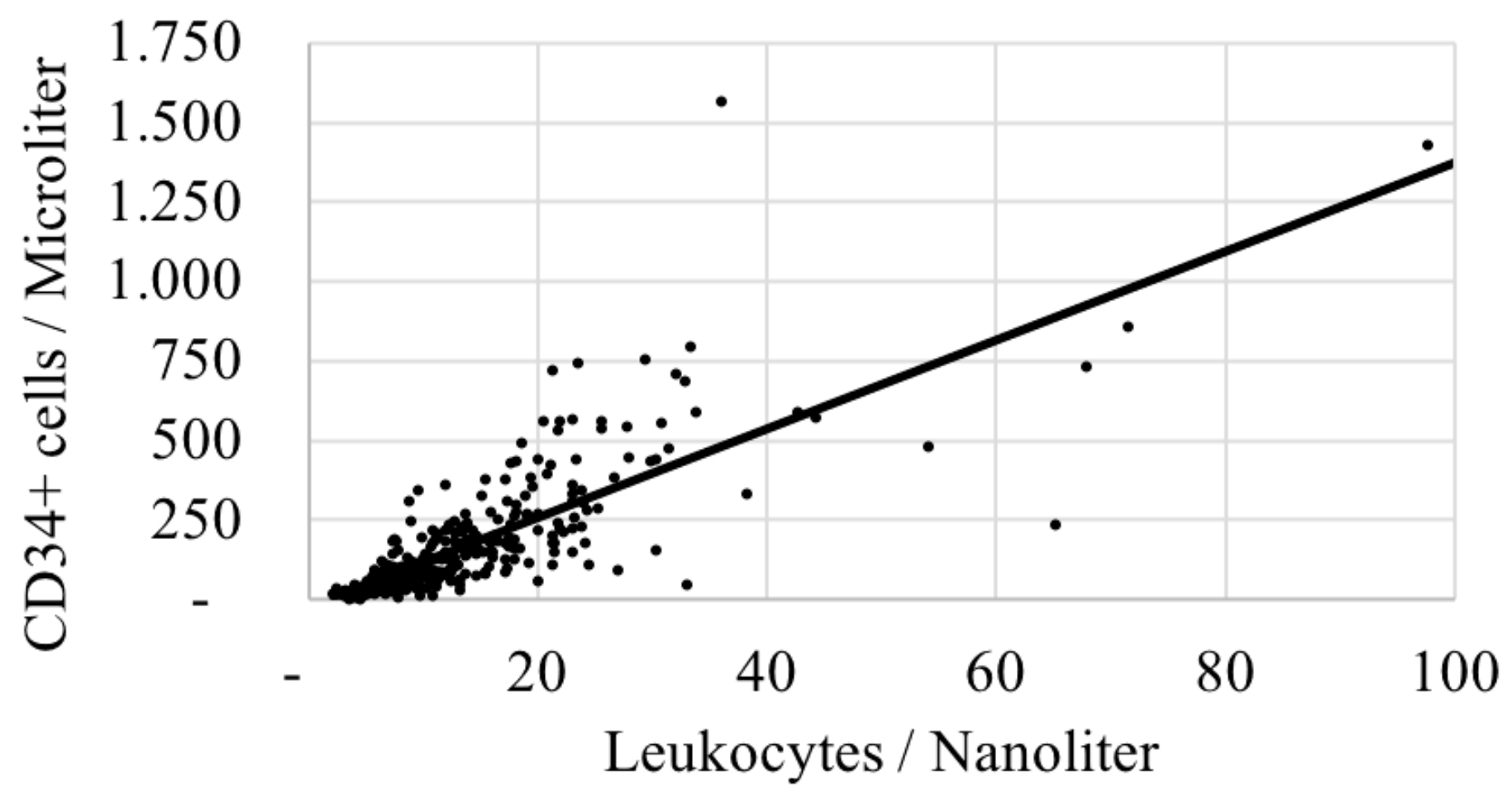

Figure 3

A strong correlation between bone marrow derived leucocytes and bone marrow derived CD34+ cells was found. 